\title{
A comparison of business meeting practices in Germany and Spain
}

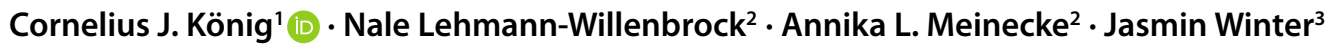

Published online: 6 August 2020

(c) The Author(s) 2020

\begin{abstract}
This article in the journal Gruppe. Interaktion. Organisation. (GIO) presents a study on meetings, an important part of contemporary organizational life. What happens in meetings affects individual employee experiences, team processes, and organizational functioning. However, to date little is known regarding cross-cultural differences in meeting practices. This study leverages an organizational sample $(N=488)$ with a German and a Spanish site to compare how pre-meeting talk, meeting design, voice in meetings, and meeting follow-up actions differ across the two cultures. Hypotheses were derived from prior intercultural theory (i.e., the GLOBE study). Following Open Science principles, the study was pre-registered. Contrary to our expectations, we found no significant differences in meeting practices between monocultural German and Spanish workplace meetings. These findings suggest that cultural differences in workplace attitudes and work practices may be diminishing in an increasingly global workplace. We sketch implications for meeting science and cross-cultural research on business practices more broadly.
\end{abstract}

Keywords Meetings $\cdot$ Cross-cultural differences $\cdot$ Meeting design $\cdot$ Meeting practices $\cdot$ Meeting procedures

\section{Ein Vergleich zwischen Arbeitsmeetings in Deutschland und Spanien}

\section{Zusammenfassung}

Dieser Beitrag der Zeitschrift Gruppe. Interaktion. Organisation. (GIO) stellt eine Studie zu Meetings vor, die einen wesentlichen Bestandteil des organisationalen Lebens in modernen Unternehmen darstellen. Was in Meetings geschieht, hat Auswirkungen auf das individuelle Erleben von Mitarbeitenden, beeinflusst Teamprozesse und wirkt sich auf die Funktionsfähigkeit von Unternehmen aus. Bisher ist jedoch wenig über interkulturelle Unterschiede in Meeting-Praktiken von Meetings bekannt. Diese Studie befragte Mitarbeitende $(N=488)$ eines internationalen Unternehmens mit Sitz in Deutschland und Spanien. Ziel war es zu vergleichen, inwiefern sich der Smalltalk vor Meetings, Meeting Design Charakteristika, die Möglichkeit zur wahrgenommenen Meinungsäußerung und die Nachbereitung von Meetings in den beiden Kulturen unterscheiden. Die untersuchten Hypothesen wurden aus einer bestehenden interkulturellen Theorie abgeleitet (nämlich der GLOBE Studie). Den Empfehlungen der Open Science Bewegung wurde entsprochen, indem die Studie pre-registriert wurde. Entgegen unseren Erwartungen konnten wir keine signifikanten Unterschiede in den Praktiken zwischen monokulturellen deutschen und spanischen Meetings feststellen. Ausgehend von Globalisierungsargumenten diskutieren wir Implikationen für die Forschung zu Meetings und zu interkultureller Forschung im Unternehmenskontext im Allgemeinen.

Schlüsselwörter Meetings $\cdot$ Interkulturelle Unterschiede $\cdot$ Meeting-Design $\cdot$ Meeting-Praktiken $\cdot$ Meetingprozesse

Cornelius J. König

ckoenig@mx.uni-saarland.de

1 AE Arbeits- und Organisationspsychologie, Universität des

Saarlandes, Campus A1 3, 66123 Saarbrücken, Germany

2 Universität Hamburg, Hamburg, Germany

3 Universität des Saarlandes, Saarbrücken, Germany 
Meetings exist in nearly every organization regardless of organizational culture, industry, or size. Organizations devote up to $15 \%$ of their personnel budgets to meetings (Rogelberg 2019). They have become a key component of employees' everyday workplace experiences, with an overall employee average of six hours per week spent in meetings and estimates of up to $80 \%$ of managers' work time consumed by various meetings (for an overview, see LehmannWillenbrock et al. 2018; Mroz et al. 2018). Hence, meetings can be viewed as the place where organizational life happens.

Yet, the ways in which organizational life is shaped by meetings, and the way specific meeting practices are applied, may vary across different cultural settings (cf. Gelfand et al. 2017). Previous empirical work in this regard is scarce, but points to potential differences in the way meetings are conducted in different national cultures as well as the need to consider culture when studying business meetings (Angouri 2010; Aritz and Walker 2010; DuBabcock and Tanaka 2013; van Eerde and Azar 2020; van Eerde and Buengeler 2015; Joardar et al. 2019; Köhler et al. 2012; Lü 2018; Murata 2014; Paletz et al. 2018). While the practice of meetings is widespread across different types of organizations and cultures, the specific aspects of how meetings are designed, how people behave as they enter the meeting space, and what happens during and after meetings may differ depending on the respective cultural setting. Comparisons of cultural practices more broadly, most prominently the GLOBE study (House and Javidan 2004), indicate that this may be the case.

To address this idea, we present empirical findings regarding potential differences in meeting practices when comparing German to Spanish monocultural face-to-face meetings. We draw from cross-cultural differences indicated by the GLOBE study as well as previous findings regarding relevant meeting practices and test our hypotheses in a large organizational sample with employees in Germany and Spain. Our findings contribute much-needed cross-cultural insights to meeting science, relieve the often U.S.-centric study focus in previous work, and offer interesting discussion points for research and practice.

\section{Culture and meeting practices}

Considering a country as a cultural setting (Hofstede 2001), this study sets out to explore possible meeting differences and similarities between Germany and Spain with regard to pre-meeting small talk, meeting design characteristics, voice in meetings, and meeting follow-up actions. Conceptually, our study is informed by the well-known GLOBE country cluster framework (House and Javidan 2004). The GLOBE project (House and Javidan 2004) addressed the fundamental question of how and why societal cultures differ. The authors were especially interesting in the link between societal culture and organizational practices as well as leadership characteristics. Cultural values and practices were collected from 62 nations across the globe. These cultural values and practices share common ground with previous classifications by Hofstede (2001) and span a total of nine dimensions, namely performance orientation, assertiveness, future orientation, humane orientation, institutional collectivism, in-group collectivism, gender egalitarianism, power distance, and uncertainty avoidance.

Brought to the meeting context, we assume that describing the respective countries in terms of these cultural dimensions helps us to understand similarities and differences in how meetings are designed, how participants behave before and during meetings, and how they follow-up on meetings. Comparing the GLOBE values of Germany and Spain, the most striking differences emerge in in-group collectivism, uncertainty avoidance, power distance, and future orientation (Brodbeck and Frese 2008; O'Connell et al. 2008). In the following, we outline how these four key dimensions relate to our focal outcome variables.

\subsection{In-group collectivism and pre-meeting small talk}

In cultures with a high degree of in-group collectivism, members show "pride, loyalty and cohesiveness in their organizations or families" (House and Javidan 2004, p. 12). Close personal relationships are valued and communicating with the members of one's own group is considered very important (Gelfand et al. 2004; Javidan et al. 2006). Comparing Germany and Spain, the GLOBE study disclosed that Spanish in comparison to German respondents reported higher values of in-group collectivism (House et al. 2004).

Relating to workplace meetings, in-group collectivisms enables insights into the relational value that is placed on workplace gatherings. Meeting scholars noted previously that in addition to serving formal goals, meetings also provide a place to socialize, network, and build relationships (Kieffer 1988; Lehmann-Willenbrock et al. 2018; Olien et al. 2015). One way to establish and maintain close workplace relationships is to engage in pre-meeting small talk, defined as the verbal and behavioral interactions that occur before the meeting begins and that do not have an explicit work or task focus (Mirivel and Tracy 2005). Typical small talk topics include the weather, family, or sports. Scholarly interest in pre-meeting talk is slowly growing, but largely driven by efforts stemming from the U.S. (Allen et al. 2014; Yoerger et al. 2015). For example, previous research showed that pre-meeting small talk is related to meeting effectiveness (Allen et al. 2014). Research on small talk in organizations more generally further showed that small talk fulfills 
important social functions as it can strengthen work group cohesion and build the ground base for other types of more formal interactions (Holmes 2000).

In terms of cross-cultural comparisons, previous research is rather sparse and did not specifically contrast German and Spanish meetings. Extrapolating from research on U.S.-American and German meetings, Germans have been described as "eschewing small talk" (Köhler et al. 2012, p. 175). Regarding within-meeting processes, findings further showed that Germans engage in little relational talk during meetings (Köhler et al. 2012; Lehmann-Willenbrock et al. 2014). Anecdotal evidence for the Germans' apparent aversion of small talk is also ubiquitous in online articles (e.g., Houghton 2017), and popular management books frequently describe Germans as efficient and direct talkers whereas Spaniards are said to be more chatty (Lewis 2006).

In sum, as respondents from countries scoring high on ingroup collectivisms value cohesion within the work group, we assume that they favor pre-meeting small talk more than respondents from low in-group collectivistic countries. We therefore expect pre-meeting small talk to be more prevalent in Spanish than in German meetings. Our first hypothesis posits:

H1 There will be more pre-meeting small talk in Spain than in Germany.

\subsection{Uncertainty avoidance and meeting design characteristics}

Uncertainty avoidance describes "the extent to which members of an organization or society strive to avoid uncertainty by relying on established social norms, rituals, and bureaucratic practices" (House and Javidan 2004, p. 11). In other words, members of high uncertainty avoidant cultures tend to fear the unknown and therefore prefer rules and regulations that provide a guidance in coping with the unpredictable. For everyday working life in organizations, this means that simple processes and coarse strategies are preferred in low uncertainty cultures, whereas emphasis is placed on formal strategies and detailed processes in countries with high levels of uncertainty (Javidan et al. 2006).

Findings from the GLOBE project disclosed that Germans have a much higher tendency to avoid uncertainty in comparison to Spaniards (House et al. 2004), which is in line with earlier cross-cultural research (Hofstede 2001). Turning to organizational meetings, the meeting leader (i.e., the person responsible for calling and facilitating the meeting) can increase certainty and orderliness by thoroughly preparing for the meeting and structuring the meeting process (Leach et al. 2009; Odermatt et al. 2013). Important meeting design characteristics include using an agenda, making sure that the meeting starts on time, choosing an appropriate meeting space, and only inviting those participants who are necessary to the meeting. Research showed that these design characteristic are vital to meeting effectiveness and meeting satisfaction (Leach et al. 2009).

Previous cross-cultural research showed that German meetings are rather formal (Köhler and Gölz 2015; Meyer 1993). Special attention is given to a detailed meeting agenda, meaning that agenda items are processed sequentially and with high accuracy (Köhler and Gölz 2015). Germans further take care not to exceed the scheduled meeting duration (Meyer 1993), manifested in procedural statements that structure the meeting process (LehmannWillenbrock et al. 2014). In Spain, on the other hand, a spirit of adventure and associated flexibility are culturally anchored (O'Connell et al. 2008). Although this does not imply that participants follow no meeting agenda (van Eerde and Buengeler 2015), we assume that overall Spaniards tend to be more comfortable with uncertainty during meetings. Based on these differences in uncertainty avoidance, we hypothesize:

H2 More meeting design characteristics will be found in Germany than in Spain.

\subsection{Power distance and voice during meetings}

Power distance is defined as "the degree to which members of an organization or society expect and agree that power should be stratified and concentrated at higher levels of an organization or government" (House and Javidan 2004 , p. 12). High power distance has been linked to hierarchical thinking, higher levels of authority, and obedience (Carl et al. 2004). Likewise, participatory decision-making is rather seen as a waste of time and not welcomed in high power distance cultures (Carl et al. 2004).

Findings from the GLOBE project revealed that Spain scored slightly higher on power distance than Germany (House et al. 2004). Transferred to organizational meetings, higher power distance implies that the meeting leader is a person of authority who not only structures the meeting process but also is responsible for decision-making. As such, meeting leaders can use the meeting to demonstrate their power and status (e.g., Rogelberg et al. 2014). Painting a more extreme picture, the meeting leader might even control meeting participation and avoid discussing differing views. Creating such a high-power meeting environment likely discourages meeting participants from showing voice. Following definitions by Hirschman (1970) and Morrison (2014), voice is the informal and discretionary communication by an employee of ideas, concerns, information about problems, or opinions about work-related issues. These voice statements challenge the status quo, are directed at the people who can take appropriate action (i.e., 
typically the supervisor), and are constructive in nature (see also Van Dyne and LePine 1998).

Although German workplace meetings are described as structured and organized, they are typically less hierarchical than assumed (Hedderich 1999). The need to defend formal authority is low in Germany (Köhler and Gölz 2015) and previous research showed that Germans are expected to voice their opinions during meetings and to take on an active role in decision making (Köhler et al. 2012; see also Yin 2002). Seen through this lens, we assume that German meeting participants are more likely to speak up with their own opinions and concerns than Spanish meeting participants who are more inclined to promote group cohesion and in-group collectivism. Our third hypothesis thus states:

H3 There will be more voice in German than in Spanish meetings.

\subsection{Future orientation and meeting follow-up actions}

Finally, this study sets out to explore the role of future orientation and workplace meetings. Future orientation describes "the degree to which individuals in organizations or societies engage in future-oriented behaviors such as planning, investing in the future, and delaying individual or collective gratification" (House and Javidan 2004, p. 12). Higher levels of future orientation are related to systematic planning and thinking in long-term intervals. Cultures low in future orientation are more opportunistic and less systematic in their planning meaning that people prefer to live in the here and now instead of making detailed plans for the future (Javidan et al. 2006).

The GLOBE project showed that Germany scores higher on future orientation than Spain (House et al. 2004). Workplace meetings are fundamental to organizational functioning and contribute to future orientation by providing structure to decision-making and tracking organizational or departmental goals (Lehmann-Willenbrock et al. 2018). During organizational meetings, we expect future orientation to manifest in detailed action plans that outline who is responsible for which task. Thus, the way meetings are followed-up on indicates future orientation by making sure that a meeting is not an isolated single event but embedded in the employees' workflow and tasks (Aksoy-Burkert and König 2015). In this sense, meeting follow-up actions seamlessly merge with preparing for the next meeting (Tropman 2003).

Köhler et al. (2012) could show that German meeting are often conducted with the intention to come up with longterm solutions that have a high level of detail. This tendency likely carries over into concrete post meeting action plans. In Latin-European countries like Spain, on the other hand, good interpersonal relationships are seen as more important than schedules (Hickson and Hugh 1995). The tendency to live in the moment and changing plans at short notice likely leads to less follow-up actions in Spanish workplace meetings. Our final hypothesis thus posits:

H4 There will be more meeting follow-up actions after German meetings compared to Spanish meetings.

\section{Method}

\subsection{Open science}

Following guidelines for Open Science, all hypotheses, variables, and analyses were pre-registered before conducting this study. The preregistration is available at http:// aspredicted.org/blind.php? $\mathrm{x}=6 \mathrm{j} 2 \mathrm{uw} 3$. The raw data supporting the conclusions of this manuscript will be made available by the authors to any qualified researcher upon request.

\subsection{Participants}

Data were gathered in a large international aerospace company, which has offices in Germany and Spain. The participating company supported this research project because informal complaints of too many meetings were very common, including complaints about problems when interacting with colleagues from the other country in meetings. Official meeting guidelines did not exist. Participation was voluntary and participants retained the right to opt out of the data gathering at any point. The sampling procedure was approved by the company's work council. A link to an online questionnaire was distributed among 1640 employees, 800 of whom worked at the German site and 840 at the Spanish site. Participants were primarily engineers.

Five hundred and twenty-five employees responded (a response rate of $31 \%$ ). After excluding 30 participants who had no German (or Spanish) nationality, six participants who mentioned that they did not follow the instructions, and one participant with an unrealistic old age of 82 , the final sample consisted of 488 participants (254 German and 234 Spanish respondents). Of these, 86 were women and 397 men, which is consistent with the typical gender distribution of the workforce in this particular industry. Participants were on average 43.65 years old $(S D=9.81)$ and worked for the company for 15.59 years $(S D=10.12)$.

Meetings in this organization were fairly large and time consuming. They contained about nine participants on average $(M=8.7$ meeting attendees, $S D=4.4)$, which is consistent with informal accounts of the meeting culture in this organization. On average, meetings took $79.8 \min (S D=49.4)$. 


\subsection{Measures}

All questionnaires were in English, which is the official language of the company where we collected the data. Participants were given the following instruction: "For the following questions, please think of a typical meeting with your manager on site that he/she leads. We define meeting as a routine team gathering that was scheduled in advance, takes place on a regular basis, has a minimum of three participants and a duration of $15 \mathrm{~min}$ up to three hours. When answering the questions, please refer only to a typical LOCAL face-to-face team meeting with colleagues from your country and your manager on site". Thus, we specifically asked participants to focus on monocultural meetings in order to avoid possible confounding effects.

Pre-meeting small talk was assessed with the eight item small talk subscale of the pre-meeting talk scale (Allen et al. 2014). A sample item is "Before a meeting begins, to what extent do you do the following: Discuss a sporting event". The response format ranged from 1 (not at all) to 5 (to a great extent).

Meeting design characteristics were measured with a seven item scale from the Zurich Meeting Questionnaire (ZMQ, Odermatt et al. 2016). Items either were answered on a dichotomous yes/no scale (e.g., for the item "The meeting ends at the agreed time") or on a five-point scale (e.g., for the item "The goals of the meeting are clearly defined", with the scale ranging from 0 to 0.25 , to 0.5 , to 0.75 , and to 1 ). An index (see Streiner 2003) was created by summing up all items.

Voice was measured with the scale developed by Allen and Rogelberg (2013). It contains seven items, and respondents have to describe how often the meeting leader shows a specific behavior during the meeting, for example "Ensure that each employee has an opportunity to speak". Response options ranged from 1 (never) to 5 (always).
Meeting follow-up actions We developed our own measurement for meeting follow-up actions as follows. First, we searched for potential topics that were mentioned in (a) meeting guide books and articles (e.g., Carlozzi 1999; Hartmann et al. 2002; Haynes 2006; Tobia and Becker 1990; Tropman 2003) and (b) in the academic literature (Aksoy-Burkert and König 2015). Second, we discussed our insights with participants at a research colloquium. Two members of the author team then developed seven items that can be found in the Appendix. Participants answered on a scale from 1 (not at all) to 5 (to a great extent).

To test the homogeneity of our new scale, we conducted a principal component analysis, extracting a single factor. Factor loadings varied between 0.65 and 0.80 , and the factor explained $55.5 \%$ of the variance, which supports a one-factor solution. An additional reliability analysis revealed a Cronbach's alpha of 0.86 . for the full sample $\left(\alpha_{\text {German sample }}=0.85 ; \alpha_{\text {Spanish sample }}=0.87\right)$.

Additional variables To ensure that our sample was similar to previous studies, we also aimed at replicating previously shown relationships of the variables pre-meeting small talk, meeting design characteristics, and voice in meetings with a main outcome variable in the field of meeting research, i.e. meeting effectiveness (cf. Allen et al. 2014; Odermatt et al. 2016; Allen and Rogelberg 2013). Meeting effectiveness was assessed with a three-item measure from Leach et al. (2009), that asks for ratings of the effectiveness of a typical meeting in terms of goal achievement (e.g., "achieving your own work goals"). Participants rated the items on a 5-point scale ranging from 1 (extremely ineffective) to 5 (extremely effective). Finally, we asked for meeting length and number of meeting attendees as well as for some demographic information.

\section{Results}

Table 1 shows the correlations between all study variables. Both meeting design characteristics and voice in meetings significantly correlated with meeting effectiveness $(r=0.46$

Table 1 Correlations Among Study Variables

\begin{tabular}{|c|c|c|c|c|c|c|}
\hline & 1 & 2 & 3 & 4 & 5 & 6 \\
\hline 1. Country & - & & & & & \\
\hline 2. Pre-meeting small talk & 0.04 & 0.83 & & & & \\
\hline 3. Meeting design characteristics & -0.06 & -0.02 & $--^{\mathrm{a}}$ & & & \\
\hline 4. Voice in meetings & 0.05 & 0.01 & $0.30 * *$ & 0.88 & & \\
\hline 5. Follow-up actions & -0.02 & 0.00 & $0.50 * *$ & $0.32 * *$ & 0.86 & \\
\hline 6. Meeting effectiveness & 0.06 & 0.02 & $0.46^{* *}$ & $0.47 * *$ & $0.57 * *$ & 0.90 \\
\hline
\end{tabular}

$N=488$. Country coding: $1=$ Germany, $2=$ Spain. Cronbach's alphas are shown in the diagonal (in italics) where applicable

$* * p<0.01$, two-tailed

aCronbach's alpha not applicable because meeting design characteristics is an index and not a scale (see Streiner 2003) 
Table 2 Differences in Study Variables Among German and Spanish Respondents

\begin{tabular}{llllll}
\hline & Germany & Spain & Cohen's $d$ & $t$-tests & $t$ value \\
\hline Pre-meeting small talk $^{\mathrm{a}}$ & $1.91(0.62)$ & $1.96(0.64)$ & -0.08 & $p=0.42$ & -0.86 \\
Meeting design characteristics $^{\mathrm{b}}$ & $5.05(1.31)$ & $4.90(1.31)$ & 0.20 & $p=0.20$ & 1.28 \\
Voice in meetings $^{\mathrm{c}}$ & $3.75(0.80)$ & $3.82(0.78)$ & -0.09 & $p=0.30$ & -1.03 \\
Follow-up actions & $3.36(0.79)$ & $3.33(0.79)$ & 0.04 & $p=0.68$ & 0.42 \\
\hline
\end{tabular}

$n_{\text {German sample }}=254, n_{\text {Spanish sample }}=234$. Standard deviations are shown in parentheses. $d f=486$

${ }^{a}$ In the original study by Allen et al. (2014), the mean was $2.03(S D=0.95)$, thus very similar

bIn Study 1 of the original study by Odermatt et al. (2016), the mean was 5.80 ( $S D=1.50)$, in their Study 25.68 (SD=1.46), and in their Study 3 $4.90(S D=1.06)$, which indicates that the means of our samples were in the expected range

${ }^{\mathrm{C}}$ In the original study by Allen and Rogelberg (2013), the mean was $3.47(S D=0.95)$, thus only slightly lower than our means

for meeting design characteristics, similar to Odermatt et al. 2016; $r=0.47$ for voice in meetings, similar to Allen and Rogelberg 2013). Furthermore, meeting follow-up actions also correlated with meeting effectiveness $(r=0.57)$. However, pre-meeting small talk was unrelated to meeting effectiveness ( $r=0.02$, unlike Allen et al. (2014), who found a correlation of 0.28 ).

Table 2 shows the means and standard deviations of the four main variables for both countries. As can be seen, the means of both samples were fairly similar. A MANOVA showed no significant differences between German and Spanish meetings, Wilks' $\lambda=0.99$, $F(4,483)=1.10, p=0.36$. Additional $t$-tests, separately run for each variable, did not result in significant differences either (see last row of Table 2). Hence, all our study hypotheses were refuted by the findings.

\section{Discussion}

In sum, this study showed that meeting practices, in terms of pre-meeting small talk, design characteristics, voice, and meeting follow-up actions, did not differ meaningfully across the two national cultures-i.e., Germany and Spain-investigated here. Counter to previous assumptions and our hypotheses, these findings suggest more similarities than differences across cultures, based on our survey data gathered in a globally operating company.

\subsection{Theoretical and practical implications}

Previous work has emphasized cross-cultural differences in workplace values, perceptions, norms, and practices (e.g., Gibson and Zellmer-Bruhn 2002; Köhler and Gölz 2015; van Eerde and Buengeler 2015). We expected differences in meeting experiences across the German and Spanish meetings included in our sample accordingly, but the results tell a different story. One possible explanation for the lack of cross-cultural differences observed in the present study concerns the globalization argument. Specifically, differences in employees' everyday experiences across cultures may be diminishing given the contemporary global workplace. Work related practices such as human resources management, marketing, and organizational development are becoming more similar across the globe, and as a result, individual work experiences tend to become more similar than different across different national cultures (e.g., Evans et al. 2011). Meetings in particular may be a practice that is becoming more aligned across cultures due to globalization trends. Yet, we would like to acknowledge that our findings are only beginning to address the cross-cultural research gap in meeting science and clearly more research is needed to fully understand the magnitude of this global trend.

Another explanation for the lack of cross-cultural differences found in our study may lie in the interplay between national and organizational culture. Our decision to survey employees of the same organization, with sites in both Germany and Spain, is in line with previous crosscultural research, particularly Hofstede's (2001) pioneering work on cultural dimensions, which was based on a large international sample of employees working at IBM. When considering different national branches of the same organization, as in the present investigation, corporate practices related to meetings may have likened business practices across different cultural contexts. In other words, organizational culture might have trumped national culture. This view can be linked to a more fundamental discussion on the role of national culture recently put forward in crosscultural research. Taras et al. (2016) performed a metaanalysis of more than 500 studies and found that national boundaries are not the most ideal aggregate for describing cultures. They found more variation within rather than between countries and consequently suggest to focus on cultures of socio-economic classes, professions, and free versus oppressed societies instead of using national boundaries as a proxy for culture (Taras et al. 2016). Combining these findings with the findings of the present study suggests that more traditional conceptualizations of national culture only have limited effects in modern workplaces-in particular, if we want to understand how employees describe and experience their meetings. Future meeting research should explore cross-cultural differences using samples from dif- 
ferent organizations and industries to more fully explore this idea. At this point, we can only speculate as to whether organizational culture might be of greater impact than national culture in determining meeting practices.

In terms of practical implications, the current study contributes to a growing body of evidence-based meeting practices. Specifically, our findings highlight that meeting design characteristics, the opportunity to actively participate in the meeting by showing voice, and meeting follow-up actions are important building blocks for increasing meeting effectiveness, both in Germany and Spain. Turning to intercultural similarities and differences in meeting practices, our findings suggest that meetings are conducted in a more similar style than expected. For organizations (like the one where we collected the data) in which complains about cross-cultural meetings are common, our study implies that there is a danger of misattribution. Although dissatisfaction with meetings might be attributed to cross-cultural differences, such attributions might not be appropriate, and organizations should rather focus on establishing better meeting practices (e.g., more meeting preparation and more meeting follow-up actions). In particular, trainings efforts targeted at leading more effective meetings could incorporate reflection components that help participants value and understand that cultural preferences for meeting practices are rather secondary in contemporary workplaces. Our findings suggest that meeting practices between cultures are just as similar as meeting practices within a specific culture.

\subsection{Limitations and future directions}

One limitation concerns our sample, because all participants came from one company. Although variance due to organizational differences is reduced (which is the logic Hofstede [e.g., 2001] uses to explain the advantages of his strategy to collect data only within IBM), it is possible that a crossculturally shared culture within this company might have overshadowed existing differences between Spain and Germany as discussed above. It should be noted that qualitative remarks from people within the company have, however, stressed how different meetings are with members of the respective other countries. The fact that these differences could not quantitatively be established in our present investigation speaks to the subtlety or nuances of cross-cultural differences and points to the need for additional qualitative research (e.g., Köhler and Gölz 2015).

A second limitation that warrants discussion concerns our measurement of meeting experiences in the two countries. Our choice to rely on attendee perceptions of various meeting aspects aligns well with prior research (e.g., Allen et al. 2014; Leach et al. 2009; Rogelberg et al. 2006). However, self-reports may be subject to several biases (Podsakoff et al. 2003). We cannot fully rule out that cultural effects in response style may have masked possible differences between the two cultures. Two commonly recognized biases in this regard include extreme responding (i.e., the tendency to select the end-points of a scale) and acquiescent responding (i.e., the tendency to agree with questions), which showed to differ as a function of national culture (Johnson et al. 2005). Over and above particular response styles, it might have been the case that the Spanish and German respondents in our study had different cultural representations of the study constructs and corresponding response scales. Looking at pre-meeting small talk, for example, meeting attendees from Spain might have a different understanding of what "a great extent" of small talk actually looks like (e.g., in terms of time spent on small talk) in comparison to meeting attendees from Germany. To circumvent these problems, we suggest that future work may pursue a more behavior-focused approach to meeting interactions and emergent interaction patterns in meetings across different cultural settings (Lehmann-Willenbrock et al. 2014; see also Kauffeld and Lehmann-Willenbrock 2012).

Future research can utilize the new scale developed in this study for capturing meeting follow-up actions. As past research emphasized the importance of action planning for meeting effectiveness (e.g., Kauffeld and Lehmann-Willenbrock 2012), our new and reliable follow-up actions scale can be a helpful tool for both research and practice to improve meeting outcomes and promote the return on investment in organizational meetings (e.g., Lehmann-Willenbrock et al. 2018). This argument is empirically supported by the significant correlation between meeting follow-up actions and meeting effectiveness: If meeting leaders care for follow-up actions, meeting attendees perceive the meeting as more productive.

Future research should also try to explain why pre-meeting small talk is sometimes uncorrelated with meeting effectiveness (as in our study) and sometimes correlated (as in Allen et al. 2014). Maybe the effectiveness of pre-meeting small talk depends on the meeting culture of the respective company. Meetings in the participating organization in which we collected the data for the present investigation were held rather often and were typically long (i.e., more than an hour). This may have reduced the need to engage in small talk in order to construct a group identity. Future research should incorporate such design characteristics and compare the role of pre-meeting small talk across a more diverse set of industries and jobs.

Funding Open Access funding provided by Projekt DEAL.

Open Access This article is licensed under a Creative Commons Attribution 4.0 International License, which permits use, sharing, adaptation, distribution and reproduction in any medium or format, as long as you give appropriate credit to the original author(s) and the source, provide a link to the Creative Commons licence, and indicate if changes were made. The images or other third party material in this article are 
included in the article's Creative Commons licence, unless indicated otherwise in a credit line to the material. If material is not included in the article's Creative Commons licence and your intended use is not permitted by statutory regulation or exceeds the permitted use, you will need to obtain permission directly from the copyright holder. To view a copy of this licence, visit http://creativecommons.org/licenses/by/4. $0 \%$.

\section{Appendix}

The meeting follow-up actions scale was introduced with "During and after a typical meeting, how often do the following actions occur?" and included the following items, answered on a scale from from 1 (not at all) to 5 (to a great extent):

- Specific actions were agreed

- It is clearly defined who is responsible for the execution of the actions

- Deadlines for the actions are set

- Meeting minutes are written up

- The minutes are distributed shortly after the meeting

- The execution of the agreed actions is monitored

- There are milestones between the meetings to monitor the execution of the agreed actions.

\section{References}

Aksoy-Burkert, F., \& König, C. J. (2015). Meeting training: a suggestion. In J. A. Allen, N. Lehmann-Willenbrock \& S. G. Rogelberg (Eds.), The Cambridge handbook of meeting science (pp. 69-89). Cambridge: Cambridge University Press.

Allen, J. A., \& Rogelberg, S. G. (2013). Manager-led group meetings: a context for promoting employee engagement. Group \& Organization Management, 38(5), 543-569. https://doi.org/10.1177/ 1059601113503040.

Allen, J. A., Lehmann-Willenbrock, N., \& Landowski, N. (2014). Linking pre-meeting communication to meeting effectiveness. Journal of Managerial Psychology, 29(8), 1064-1081. https://doi.org/10. 1108/JMP-09-2012-0265.

Angouri, J. (2010). 'If we know about culture it will be easier to work with one another': developing skills for handling corporate meetings with multinational participation. Language and Intercultural Communication, 10(3), 206-224. https://doi.org/10. 1080/14708470903348549.

Aritz, J., \& Walker, R.C. (2010). Cognitive organization and identity maintenance in multicultural teams: a discourse analysis of decision-making meetings. Journal of Business Communication, 47(1), 20-41. https://doi.org/10.1177/0021943609340669

Brodbeck, F. C., \& Frese, M. (2008). Societal culture and leadership in Germany. In J.S. Chhokar, F. C. Brodbeck \& R. J. House (Eds.), Culture and leadership across the world: The GLOBE book of in depth studies of 25 societies (pp. 147-214). Mahwah: Erlbaum.

Carl, D., Vipin, G., \& Javidan, M. (2004). Power distance. In R. J. House, P. J. Hanges, M. Javidan, P. W. Dorfman \& V. Gupta (Eds.), Culture, leadership, and organizations: the GLOBE study of 62 societies (pp. 513-563). Thousand Oaks: SAGE.

Carlozzi, C. L. (1999). Make your meetings count. Journal of Accountancy, 187(2), 53-55.
Du-Babcock, B., \& Tanaka, H. (2013). A comparison of the communication behaviors of Hong Kong Chinese and Japanese business professionals in intracultural and intercultural decision-making meetings. Journal of Business and Technical Communication, 27(3), 263-287. https://doi.org/10.1177/1050651913479918.

Van Dyne, L., \& LePine, J. A. (1998). Helping and voice extra-role behaviors: evidence of construct and predictive validity. Academy of Management Journal, 41(1), 108-119. https://doi.org/10.5465/ 256902.

van Eerde, W., \& Azar, S. (2020). Too late? What do you mean? Cultural norms regarding lateness for meetings and appointments. Cross-Cultural Research, 54(2-3), 111-129. https://doi.org/10. 1177/1069397119866132.

van Eerde, W.A., \& Buengeler, C. (2015). Meeting preparation and design characteristics. In J. A. Allen, N. Lehmann-Willenbrock \& S. G. Rogelberg (Eds.), The Cambridge handbook of meeting science (pp. 177-202). Cambridge: Cambridge University Press.

Evans, P., Pucik, V., \& Bjorkman, I. (2011). The global challenge: international human resource management (2nd edn.). New York: McGraw-Hill.

Gelfand, M. J., Aycan, Z., Erez, M., \& Leung, K. (2017). Cross-cultural industrial organizational psychology and organizational behavior: a hundred-year journey. Journal of Applied Psychology, 102(3), 514-529. https://doi.org/10.1037/apl0000186.

Gelfand, M. J., Bhawuk, D. P. S., Nishii, L. H., \& Bechtold, D. J. (2004). Individualism and collectivism. In R. J. House, P. J. Hanges, M. Javidan, P.W. Dorfman \& V. Gupta (Eds.), Culture, leadership, and organizations: The GLOBE study of 62 societies (pp. 437-512). Thousand Oaks: SAGE.

Gibson, C. B., \& Zellmer-Bruhn, M. E. (2002). Minding your metaphors: applying the concept of teamwork metaphors to management of teams in multicultural contexts. Organizational Dynamics, 31(2), 101-116. https://doi.org/10.1016/S0090-2616(02)00095-5.

Hartmann, M., Röpnack, R., \& Baumann, H.-W. (2002). Immer diese Meetings! [Always these meetings!]. Weinheim: Beltz.

Haynes, M.E. (2006). Meeting skills for leaders: a practical guide for more productive meetings (3rd edn.). Boston: Course Technology.

Hedderich, N. (1999). When cultures clash: views from the professions. Die Unterrichtspraxis/Teaching German, 32(2), 158-165. https://doi.org/10.2307/3531756.

Hickson, D. J., \& Hugh, D. S. (1995). Management worldwide: the impact of societal culture on organizations around the globe. Harmondsworth: Penguin.

Hirschman, A. O. (1970). Exit, voice, and loyalty: responses to decline in firms, organizations, and states. Cambridge: Harvard University Press.

Hofstede, G. (2001). Culture's consequences: comparing values, behaviors, institutions and organizations across nations (2nd edn.). Thousand Oaks: SAGE.

Holmes, J. (2000). Doing collegiality and keeping control at work: small talks in government deparments. In J. Coupland (Ed.), Small talk (pp. 32-61). Harlow: Pearson.

Houghton, N. (2017). Annoying the Germans: small talk. http:// 40percentgerman.com/home/2017/11/27/annoying-the-germanssmall-talk. Accessed 14 June 2019.

House, R. J., \& Javidan, M. (2004). Overview of GLOBE. In R. J. House, P. J. Hanges, M. Javidan, P. W. Dorfman \& V. Gupta (Eds.), Culture, leadership, and organizations: The GLOBE study of 62 societies (pp. 9-28). Thousand Oaks: SAGE.

House, R.J., Hanges, P.J., Javidan, M., Dorfman, P.W., \& Gupta, V. (Eds.). (2004). Culture, leadership, and organizations: the GLOBE study of 62 societies. Thousand Oaks: SAGE.

Javidan, M., Dorfman, P.W., Sully de Luque, M., \& House, R.J. (2006). In the eye of the beholder: cross cultural lessons in leadership from project GLOBE. Academy of Management Perspectives, 20(1), 67-90. https://doi.org/10.5465/amp.2006.19873410.

Joardar, A., Jamro, K., \& Ravi, R. (2019). The business meeting: a cross-cultural experiential learning activity. Organization 
Management Journal, 16(4), 338-349. https://doi.org/10.1080/ 15416518.2019.1663143.

Johnson, T., Kulesa, P., Cho, Y.I., \& Shavitt, S. (2005). The relation between culture and response style: evidence from 19 countries. Journal of Cross-Cultural Psychology, 36(2), 264-277. https:// doi.org/10.1177/0022022104272905.

Kauffeld, S., \& Lehmann-Willenbrock, N. (2012). Meetings matter: effects of team meetings on team and organizational success. Small Group Research, 43(2), 130-158. https://doi.org/10.1177/ 1046496411429599.

Kieffer, G. D. (1988). The strategy of meetings. New York: Warner.

Köhler, T., \& Gölz, M. (2015). Meetings across cultures: cultural differences in meeting expectations and processe. In J. A. Allen, N. Lehmann-Willenbrock \& S. G. Rogelberg (Eds.), The Cambridge handbook of meeting science (pp. 119-152). Cambridge: Cambridge University Press.

Köhler, T., Cramton, C.D., \& Hinds, P. J. (2012). The meeting genre across cultures: Insights from three German-American collaborations. Small Group Research, 43(2), 159-185. https://doi.org/10. 1177/1046496411429600.

Leach, D., Rogelberg, S., Warr, P., \& Burnfield, J. (2009). Perceived meeting effectiveness: the role of design characteristics. Journal of Business and Psychology, 24(1), 65-76. https://doi.org/10. 1007/s10869-009-9092-6.

Lehmann-Willenbrock, N., Allen, J. A., \& Meinecke, A. L. (2014). Observing culture: differences in U.S.-American and German team meeting behaviors. Group Processes \& Intergroup Relations, 17(2), 252-271. https://doi.org/10.1177/1368430213497066.

Lehmann-Willenbrock, N., Rogelberg, S. G., Allen, J. A., \& Kello, J.E. (2018). The critical importance of meetings to leader and organizational success: evidence-based insights and implications for key stakeholders. Organizational Dynamics, 47(1), 32-36. https://doi. org/10.1016/j.orgdyn.2017.07.005.

Lewis, R. (2006). When cultures collide: leading across cultures. London: Brealey.

Lü, P.H. (2018). When different "codes" meet: communication styles and conflict in intercultural academic meetings. Language \& Communication, 61, 1-14. https://doi.org/10.1016/j.langcom. 2017.10.001.

Meyer, H.-D. (1993). The cultural gap in long-term international work groups: a German-American case study. European Management Journal, 11(1), 93-101. https://doi.org/10.1016/02632373(93)90029-H.

Mirivel, J.C., \& Tracy, K. (2005). Premeeting talk: an organizationally crucial form of talk. Research on Language and Social Interaction, 38(1), 1-34. https://doi.org/10.1207/s15327973rlsi3801_1.

Morrison, E.W. (2014). Employee voice and silence. Annual Review of Organizational Psychology and Organizational Behavior, 1(1), 173-197. https://doi.org/10.1146/annurev-orgpsych031413-091328.

Mroz, J.E., Allen, J.A., Verhoeven, D.C., \& Shuffler, M.L. (2018). Do we really need another meeting? The science of workplace meetings. Current Directions in Psychological Science, 27(6), 484-491. https://doi.org/10.1177/0963721418776307.

Murata, K. (2014). An empirical cross-cultural study of humour in business meetings in New Zealand and Japan. Journal of Pragmatics, 60, 251-265. https://doi.org/10.1016/j.pragma.2013.09. 002.

O'Connell, J. J., Prieto, J. M., \& Gutierrez, C. (2008). Managerial culture and leadership in Spain. In J. S. Chhokar, F. C. Brodbeck \& R. J. House (Eds.), Culture and leadership across the world: the GLOBE book of in depth studies of 25 societies (pp. 623-654). Mahwah: Erlbaum.

Odermatt, I., Kleinmann, M., König, C. J., \& Giger, K. P. (2013). Erfolgreiche Meetingvorbereitung: Worauf kommt es an? [Successful meeting preparation: What matters?]. Report Psychologie, 38(1), $8-16$.
Odermatt, I., König, C. J., \& Kleinmann, M. (2016). Development and validation of the Zurich Meeting Questionnaire (ZMQ). European Review of Applied Psychology, 66(5), 219-232. https://doi.org/10. 1016/j.erap.2016.06.003.

Olien, J. L., Rogelberg, S. G., Lehmann-Willenbrock, N., \& Allen, J. A. (2015). Exploring meeting science: key questions and answers. In J. A. Allen, N. Lehmann-Willenbrock \& S. G. Rogelberg (Eds.), The Cambridge handbook of meeting science (pp. 12-19). Cambridge: Cambridge University Press.

Paletz, S.B., Sumer, A., \& Miron-Spektor, E. (2018). Psychological factors surrounding disagreement in multicultural design team meetings. CoDesign, 14(2), 98-114. https://doi.org/10.1080/ 15710882.2017.1378685.

Podsakoff, P.M., MacKenzie, S.B., Lee, J.Y., \& Podsakoff, N.P. (2003). Common method biases in behavioral research: a critical review of the literature and recommended remedies. Journal of Applied Psychology, 88(5), 879-903. https://doi.org/10.1037/ 0021-9010.88.5.879.

Rogelberg, S. G. (2019). The surprising science of workplace meetings. New York: Oxford University Press.

Rogelberg, S. G., Scott, C. W., Agypt, B., Williams, J., Kello, J.E., McCausland, T., et al. (2014). Lateness to meetings: examination of an unexplored temporal phenomenon. European Journal of Work and Organizational Psychology, 23(3), 323-341. https://doi.org/ 10.1080/1359432x.2012.745988.

Rogelberg, S. G., Leach, D. J., Warr, P. B., \& Burnfield, J. L. (2006). "Not another meeting!" Are meeting time demands related to employee well-being? Journal of Applied Psychology, 91(1), 86-96. https://doi.org/10.1037/0021-9010.91.1.83.

Streiner, D.L. (2003). Being inconsistent about consistency: When coefficient alpha does and doesn't matter. Journal of Personality Assessment, 80(2), 217-222. https://doi.org/10.1207/ S15327752JPA8003_01.

Taras, V., Steel, P., \& Kirkman, B.L. (2016). Does country equate with culture? Beyond geography in the search for cultural boundaries. Management International Review, 56(4), 455-487. https://doi. org/10.1007/s11575-016-0283-x.

Tobia, P. M., \& Becker, M. C. (1990). Making the most of meeting time. Training \& Development Journal, 44(8), 34-38.

Tropman, J.E. (2003). Making meetings work: achieving high quality group decisions (2nd edn.). Newbury Park: Sage.

Yin, J. (2002). Telling the truth? A cultural comparison of "facilitating discussion" in American talk. Discourse Processes, 33(3), 235-256. https://doi.org/10.1207/s15326950dp3303_3.

Yoerger, M.A., Francis, K., \& Allen, J.A. (2015). So much more than "chit-chat": a closer look at premeeting talk. In J. A. Allen, N. Lehmann-Willenbrock \& S.G. Rogelberg (Eds.), The Cambridge handbook of meeting science (pp. 153-173). Cambridge: Cambridge University Press. 


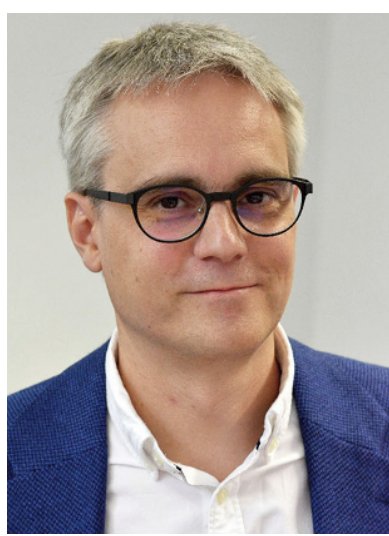

Cornelius J. König is professor for industrial/organizational psychology at Universität des Saarlandes in Saarbrücken, Germany. His main research interests are personnel selection, job insecurity/firing, and time management (including meetings).

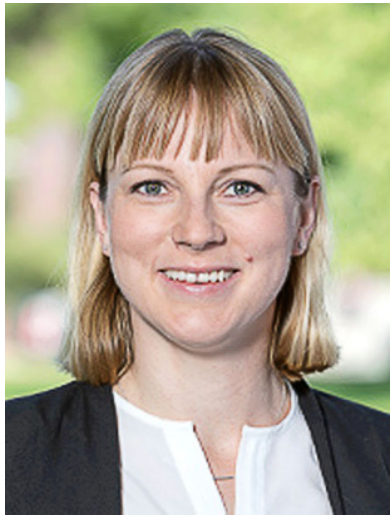

Nale Lehmann-Willenbrock is professor of Industrial/Organizational psychology at the University of Hamburg, Germany. Her research interests include workplace meetings, behavioral team processes, and leader-follower dynamics in organizations.

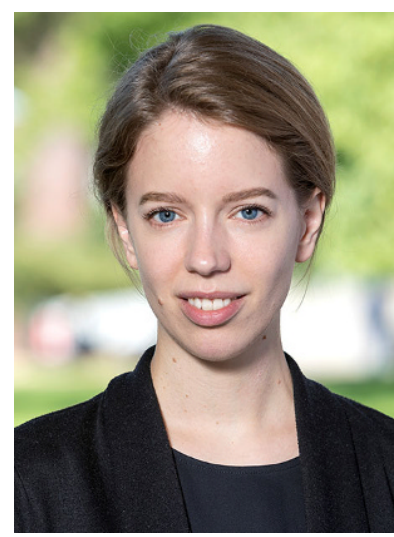

Annika L. Meinecke is a postdoctoral research fellow at the Department of Industrial/Organizational Psychology at the University of Hamburg, Germany. Her research focuses on leader-follower dynamics, team processes, and workplace gossip.

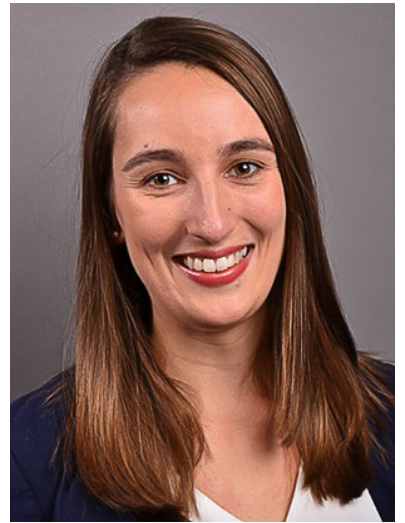

Jasmin Winter was a Master student at the Unversität des Saarlandes in Saarbrücken, Germany, focusing on industrial/organizational psychology. 